Research Article

\title{
A study of lung resection for haemoptysis with or without pre-operative bronchial artery embolisation
}

\author{
Alluru Sarath Chandra*, Kashipaka Rajalingam, K. Bhaskar Reddy V., \\ P. Kameswari Prasad
}

Department of Surgery, Malla Reddy Institute of Medical Sciences, Hyderabad, Telangana, India

Received: 29 January 2016

Revised: 21 April 2016

Accepted: 03 June 2016

\section{*Correspondence:}

Dr. Alluru Sarath Chandra,

E-mail: allurusarath@gmail.com

Copyright: (c) the author(s), publisher and licensee Medip Academy. This is an open-access article distributed under the terms of the Creative Commons Attribution Non-Commercial License, which permits unrestricted non-commercial use, distribution, and reproduction in any medium, provided the original work is properly cited.

\begin{abstract}
Background: Massive and recurrent haemoptysis are associated with extreme mortality. Most authors concede that massive haemoptysis is defined as coughing out of blood $600 \mathrm{ml}$ in 24 hours or $250 \mathrm{ml}$ in a single bout. Recurrent haemoptysis is the one condition where the patient coughs out significant amount of blood more than once. Both these conditions are associated with $30 \%$ to $50 \%$ mortality. The objective of this review is to evaluate the outcome of lung resection for haemoptysis with or without pre-operative bronchial artery embolisation (B.A.E.). It may be advisable to bypass the B.A.E. and proceed directly to lung resection.

Methods: Retrospective review of case records from March, 2008 to March 20015, admitted to the department of Cardiothoracic Surgery with haemoptysis (3 cases of massive and 15 cases of recurrent haemoptysis) deemed suitable for lung resection was undertaken. When B.A.E was undertaken the lung resection was necessitated due to recurrent haemoptysis.

Results: 18 Patients with significant haemoptysis (massive 3, recurrent 15) were evaluated 15 patients had lung resection without B.A.E and 3 patients following B.A.E had recurrent haemoptysis needing lung resection. None of the patients developed recurrence after surgery and one patient had empyema thoracis which was drained.

Conclusions: The lung resection is feasible in appropriately selected cases with radiologically localized disease and haemoptysis. This study suggests that B.A.E is probably best utilized as a temporary measure to control bleeding.
\end{abstract}

Keywords: BAE, Lobectomy, Haemoptysis

\section{INTRODUCTION}

Massive and recurrent haemoptysis are associated with extreme mortality. Most authors concede that massive haemoptysis is defined as coughing out of blood $600 \mathrm{ml}$ in 24 hours or $250 \mathrm{ml}$ in a single bout. ${ }^{1}$ Recurrent haemoptysis is the one condition where the patient coughs out significant amount of blood more than once. Both these conditions are associated with $30 \%$ to $50 \%$ mortality. ${ }^{2}$ The risk of death in haemoptysis is due to asphyxiation by flooding of blood into traechobronchial tree rather than exsanaguation and hypovolemia. ${ }^{3,4}$ In cases of haemoptysis, the role of B. A. E preceding surgery is not well defined. ${ }^{5-7}$ Other treatment modalities for haemoptysis include ice cold lavage of the air ways, instillation of vasoconstrictors into the bronchial tree, radiotherapy in case of massive haemoptysis in non resectable bronchial carcinoma and instillation of intravenous anti-fungal agents into the mycetoma containing cavities of the lung. These measures were done on small group of patients and appear insignificant for routine usage. The lung resection by and large yields greater percentage of cure rates compared to any other modality of treatment. The common causes of significant 
haemoptysis are T.B, aspergilloma, bronchiectasis, bronchogenic carcinoma, and few cases of necrotizing lung infections. The haemoptysis can be due to involvement of bronchial arteries, pulmonary arteries and in few cases intercostal arteries. ${ }^{8}$ The pulmonary arterial network cannot undergo vasospam as affectively as bronchial vessel network, The valves of the pulmonary vessels are thin and hence do not contract. The vasoactive drugs or physical agents like ice have mild effect. The bronchial arterial ulcerations usually produce massive haemoptysis since arteries directly arise from the Aorta. The B. A. E is ideally suited for the cases where the disease predominantly involves the bronchial vessels e.g. Bronchogenic Carcinoma. Other surgical modality available is physiological lung exclusions and may be an alternative measure in cases of dense vascular adhesions and pleural fibrosis. ${ }^{9}$ In some centers isolation of the bleeding bronchus was done by endoluminal blocking of bleeding site with the help of a double lumen endo tracheal tube which is purely temporary methods.

\section{METHODS}

18 cases of significant haemoptysis (3 massive, 15 recurrent) which presented to cardio thoracic surgery department between March, 2008 to March, 2015 and the outcome of these cases after lung resection was analyzed. We consider the haemoptysis to be massive when there is expectoration of $600 \mathrm{ml}$ of blood over 24 hours, significant when patient expectorates more than $100 \mathrm{ml}$ or when recurrent. The main objective of the treatment is to prevent asphyxiation, to localize the site of bleeding, to stop hemorrhage, to determine the etiology of the haemoptysis and to prevent the recurrence of the haemoptysis. The main stay of treatment in this series was surgery. ${ }^{3}$ patients underwent B. A. E ( 2 for massive haemoptysis and one for recurrent haemoptysis) by the interventional cardiologist. All the 3 cases had recurrent haemoptysis within 72 hours of B. A. E. Baseline investigations like heamatology, biochemistry and clotting tests were done. Collected sputum was stained for bacteria, acid fast bacilli and fungi. Chest X-ray was done in all cases. Bronchoscope was performed in all cases. The objective was to see the cause of bleeding, to localize the site of bleeding and carryout control methods like adrenaline saline lavage and ice cold lavage. CT Scan of the chest was performed in all 18 cases. P. F. T was done in all cases and cases with mild to moderate pulmonary restriction were taken up for surgery. Very severe restricted pulmonary reserve cases were not accepted for surgery. In case of massive haemoptysis the isolation of the bleeding lung from healthy lung was achieved by double lumen endotracheal tube. All the 18 patients were admitted to intensive care unit of the CT surgery department. There were 14 men and 4 women in this study. The causes of haemoptysis were TB 12 cases, bronchiectasis 4 cases, bronchogenic carcinoma 2 cases and 2 cases of aspergillosis in chronic tuberculous cavities.

\section{Inclusion criteria}

- $\quad$ H.b. $\%>10 \mathrm{gm} \%$

- $\mathrm{PAO} 2>60 \%, \mathrm{PCO} 2<45 \%$

- $\quad$ L. F. T and R. F. T - within normal limits

- Radiologically operable cases were included.

\section{Exclusion criteria}

- H. I. V positive cases were excluded

- Haemorrhages of extra pulmonary causes like coagulopathies

\section{Surgical methods}

In this series 3 cases were subjected to B. A. E ( 2 massive haemoptysis and one was recurrent) and all the three cases ended up with recurrent significant (>100ml) haemoptysis. In this series irrespective of pre-operative embolization all the cases were subjected to lung resection. In one case right pneumonectomy was done and in another case left pneumonectomy. 16 cases underwent lobectomies. The right upper lobectomy was carriedout in 7 cases and left upper lobectomy was carried out in 6 cases. Right middle lobectomy was done in 1 case and lower and middle lobectomy was done one case and in another case left lower lobectomy was done. The outcome between surgery and surgery with B. A. E is compared as below.

\section{RESULTS}

Table 1: Comparison of surgery with B. A. E and outcome.

\begin{tabular}{|lll|}
\hline Surgery & 15 cases & Good (mortality Nil) \\
\hline With B. A. E & 3 cases & Recurrent haemoptysis \\
\hline
\end{tabular}

Table 1 comparison of surgery with B. A. E. and outcome. It was found that out of 15 cases that underwent surgery i.e. out of 15 none died or had recurrent hemoptysis. Those who underwent B. A. E. prior to surgery developed recurrent haemoptysis i.e. $100 \%$.

Table 2: Age distribution of study subjects.

\begin{tabular}{|l|l|}
\hline Age/years & No of cases \\
\hline $0-12$ & 1 case \\
\hline $12-24$ & 6 cases \\
\hline $25-35$ & 5 cases \\
\hline $35-55$ & 5 cases \\
\hline 55 and above & 2 cases \\
\hline
\end{tabular}

Maximum cases were in the age group of 12-24 years followed by 5 cases each in the age group of 25-35 and 35-55 years. 
Table 3: Sex distribution of study subjects.

\begin{tabular}{|ll|}
\hline Male & Female \\
\hline $14(77.7 \%)$ & $4(22.3 \%)$ \\
\hline
\end{tabular}

Maximum were males i.e. $77.7 \%$. The male to female ratio was 3.5:1.

Table 4: Etiology wise distribution of cases.

\begin{tabular}{|lll|}
\hline 1 & Bronchogenic carcinoma & 2 cases \\
\hline 2 & Bronchiectasis & 4 cases \\
\hline 3 & Tuberculosis (pulmonary) & 12 cases \\
\hline 3A & T.B. cavity with fungus ball & 2 cases \\
\hline 3B & T.B cavity without fungus & 10 cases \\
\hline
\end{tabular}

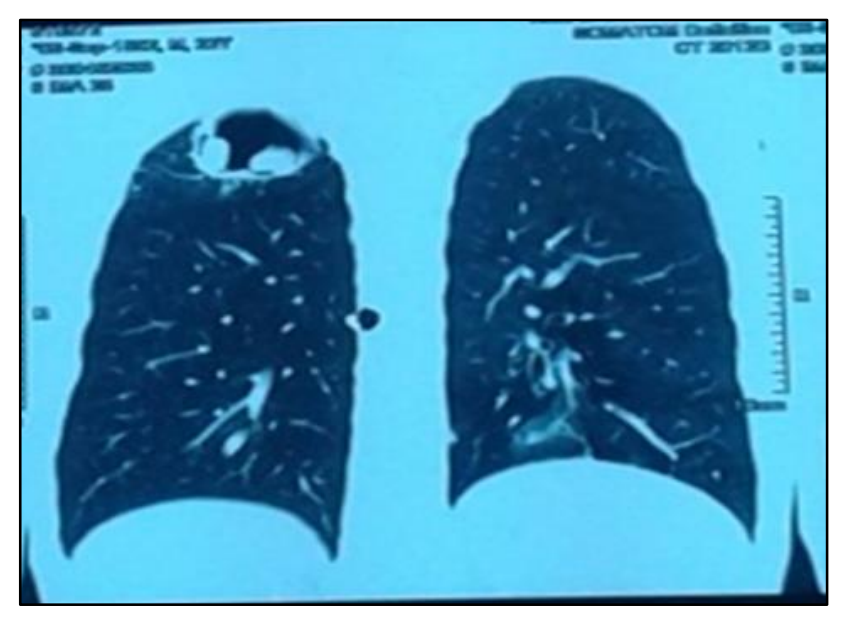

Figure 1: CT scan of the fungus ball.

The commonest cause of hemoptysis was tuberculosis followed by bronchiectasis.

All the patients are under followup and none had haemoptysis post operatively during our followup period. 2 cases of bronchogenic carcinoma were subjected to chemo radiation.

\section{DISCUSSION}

Haemoptysis in our country is more often due to tuberculosis. The other causes are bronchiectasis, bronchogenic carcinoma, aspergillosis and necrotizing pneumonitis. ${ }^{10,11}$ Blood flooding into tracheo bronchial tree may be due to erosion of the pulmonary arteries, bronchial arteries and sometimes due to intercostal artery erosions (aspergillosis). In case where there is a bleeding from the bronchial artery, embolization of the bronchial artery might temporarily seal the bleeding vessel. However this is not useful in case of pulmonary artery and intercostal artery involvement. Nearly $50 \%$ of cases following B.A.E usually end up with recurrent haemoptysis. However in our study all the 3 cases $(100 \%)$ ended up with recurrent haemoptysis. This is not statistically significant since the number is low.
Pulmonary arteries don't go into vasospam compared to bronchial vessels. The wall of the pulmonary vessels are thin and there is no active contraction. Some clues may predict the bleeding of pulmonary artery origin examples being fungal ball, lung abscess, presence of cavity with emptying and refilling sign. In all these cases it is recommended to subject the patient to surgery alone. In case of pulmonary vessel haemorrage the operation must be done immediately. In cases of a localized lesion with haemoptysis surgery is the treatment of choice. Two of our cases with massive haemoptysis required emergency surgery. One ended up with right pneumonectomy and in other case right upper lobectomy was carried out. None of the cases in this series ended-up with recurrent haemoptysis. The reason probably is that surgery takes care of bleeding both from bronchial and pulmonary vessels, whereas B.A.E is useful only in cases with bronchial artery bleeding. All the cases in this series were given adequate amount of blood transfusions. Only 1 case had post resection residual empyema which was drained with I.C.D insertion.

Alexander GR reported that sixty-one patients with massive haemoptysis were deemed suitable for emergency lung resection. ${ }^{12}$ Forty-one patients had lung resection without BAE. One patient $(2 \%)$ had recurrent minor haemoptysis after surgery. Other complications included 2 deaths, 1 post-resection empyema thoracis and 1 deep thoracotomy wound infection. Twenty patients underwent surgery following BAE. Fifteen (75\%) patients had recurrent haemoptysis after BAE. None developed recurrent haemoptysis after surgery. Other complications included 1 death and 2 post-resection empyema thoraces.

Kim YG et al found that of the 118 patients, $112(95.8 \%)$ had haemoptysis of greater than $100 \mathrm{~mL}$ per day. ${ }^{13}$ The most common underlying cause of haemoptysis was pulmonary tuberculosis. Eight patients, four of whom had advanced lung cancer, died after BAE. There were 32 patients $(27.1 \%)$ in the re-bleeding group. Aspergillosis was significantly associated with re-bleeding after BAE $(\mathrm{P}<0.05)$. There were no differences in gender, age, degree of haemoptysis, or APACHE II scores between the re-bleeding and non-rebleeding groups. Twelve patients in the re-bleeding group had a repeat BAE only, whereas seven underwent surgery after repeat BAE. Of the 118 patients who underwent initial BAE, one showed a transient spinal ischaemia.

Chun JY et al observed that the most frequent causes of haemoptysis included bronchiectasis (16\%), active tuberculosis $(12 \%)$ and aspergilloma $(12 \%) .{ }^{14}$ A total of 126 bronchial and non-bronchial systemic arteries were embolised in 62 procedures. Immediate cessation of haemoptysis was achieved in 43 patients $(86 \%)$. Haemoptysis was controlled in 36 patients (72\%), recurred in $14(28 \%)$ and $11(22 \%)$ required repeat embolisation. The worst outcomes were observed in patients with aspergilloma: all six suffered recurrent 
bleeding and three (50\%) died from massive haemoptysis. Aspergilloma was also associated with an increased risk of haemoptysis recurrence $(p<0.05)$. A good clinical outcome was achieved in those with active tuberculosis and malignancy. Complication rates were low and included transient chest pain, false aneurysm and one case of lower limb weakness.

Lee $\mathrm{JH}$ et al found that chronic TB patients had higher numbers of total feeding vessels $(4.40+$ or -3.85 versus $1.79+$ or $-1.51, \mathrm{P}=0.007)$ and NBSA $(1.57+$ or -1.63 versus $0.42+$ or $-0.61, \mathrm{P}=0.005)$ than the bronchiectasis patients. ${ }^{15}$ The number of embolisations required for obliterating feeding vessels $(3.87+$ or -2.48 versus 1.95 + or $-1.47, \mathrm{P}=0.004)$, and the incidence of incomplete embolisation $(30 \%$ versus $5.3 \%, \mathrm{P}=0.033)$ were also higher in the TB patients. Moreover, recurrence after BAE was more frequent in the TB patients $(17 / 30,56.7 \%$ versus $5 / 19,26.3 \%, \mathrm{P}=0.037)$. Male sex, past history of haemoptysis and incomplete embolisation during BAE were associated with higher recurrence of haemoptysis in chronic TB patients. The existence of a fungus ball or significant pleural thickening ( $>$ or $=10 \mathrm{~mm}$ ) was not found to influence the recurrence rate of haemoptysis.

Slattery $\mathrm{MM}$ et al reported that $\mathrm{BAE}$ resulted in an immediate cessation of haemoptysis in $7(88 \%)$ patients. ${ }^{16}$ Long-term control of bleeding was achieved in five of these patients. Rebleeding occurred within 24 hours in one patient, and two patients had recurrence of haemoptysis at 6 months and 1 year, respectively. In these three patients, repeat embolisation succeeded in the immediate control of haemoptysis, and no rebleeding was reported at 1 year follow up.

Kaukuntla HK et al observed that Indications were failure to stabilize the bronchial arterial catheter for BAE (three cases), recurrence after BAE previously controlled bleeding (one case), and communication with the right costocervical trunk signifying risk to the spinal circulation (one case). ${ }^{17}$ The mean follow-up was 68 months (range 3-144 months). There was one death in this series, a patient who was asphyxiated with hemoptysis, requiring ventilation preoperatively. $\mathrm{He}$ underwent successful extrapleural thoracotomy for bronchial artery ligation, with no further bleeding but succumbed to severe chest infection and multiorgan failure a few days later. Two patients had recurrent bleeding 12 and 36 months after surgery. Selective bronchial angiography proved the contralateral bronchial arteries to be the culprit. Extrapleural bronchial artery ligation is an effective method of controlling hemoptysis in $\mathrm{CF}$, when BAE has failed.

Cipolli $\mathrm{M}$ et al stated that our experience indicates that massive and/or recurrent hemoptysis in CF patients can be safely and effectively managed by BAE if the procedure is performed by a skilled practitioner. ${ }^{18}$ The procedure was well tolerated and resulted in prolonged and satisfactory bleeding control in most patients.
Vidal $\mathrm{V}$ et al concluded that despite the effectiveness of embolization in controlling recurrent or major hemoptysis, adults with cystic fibrosis who have undergone BAE for hemoptysis are at much higher risk of respiratory function aggravation, death, and the need for lung transplantation than those who have not undergone BAE for hemoptysis. ${ }^{19}$ They are more likely to die or to undergo lung transplantation than to present with recurrent major hemoptysis.

Barben JU et al concluded that Massive haemoptysis was unrelated to the severity of lung disease and was more likely to be treated with embolisation. ${ }^{20} \mathrm{BAE}$ was highly effective, however, $46 \%$ of the children required reembolisation at some time, which is similar to the recurrence risk for major hemoptysis treated conservatively on longer term follow-up.

\section{CONCLUSION}

Surgery for Haemoptysis for both recurrent and massive yields good results. The other methods employed for haemoptysis like B.A.E, Cold water instillation intrabronchially at best are temporary methods. These methods may fail to control bleeding and may result in recurrent haemoptysis.

Funding: No funding sources

Conflict of interest: None declared

Ethical approval: The study was approved by the institutional ethics committee

\section{REFERENCES}

1. Jougon J, Ballester M, Delcambre F, Mac Bride T, Valat P, Gome F, et al. Massive hemoptysis: what place for medical and surgical treatment. Eur $\mathbf{J}$ Cardio-Thoracic Surg. 2002;22:345-51.

2. Knott-craig Cl, Oostuizen JG, Rossouw G, Jouberi JR, Barnard PM. Management and prognosis of massive hemoptysis. Recent experience with 120 patients. J Thorac Cardiovase Surg. 1993;105:394-7.

3. Shigemura N, Wan IV, Yu SC, Wong RH, Hsin MK, Tung HK, et al. Multidisciplinary management of life threatening massive haemoptysis; a 10 year experience. Ann Throac Surg. 2009;87:849-53.

4. Grouth A, Garzon A. Operative treatment of massive haemoptysis. Ann Thoriac Surg. 1974;18:52-60.

5. Remy J, Arnaud A, Fardou H, Giraud R, Voisin C. Treatment of hemoptysis by embolisation of bronchial arteries. Radiology. 1977;122:33-7.

6. Saumench J, Escarrabill J, Padro L, Montana J, Clariana A, Canto A. Value of fiberoptic bronchoscopy and angiography for diagnosis of the bleeding site in hemoptysis. Ann Thorac Surg. 1989;48:272-4.

7. Mal H, Rullon L, Mellot F, Brugiere O, Sleiman C, Menu Y, et al. Immediate and long - term results of 
bronchial artery embolisation for life threatening hemoptysis. Chest. 1999;115:996-1001.

8. Haworth SG, De Leval M, Macartny FJ. How the left lung is perfused after ligating the left pulmonary artery in the pig at birth clinical implications for the hypoperfoused lung. Candiovasc Dis. 1981;15:21426.

9. Dhaliwal RS, Saxena P, Puri D, Sidhu KS. Role of physiological lung exclusion in difficult long resections for massive hemiotysis and other problems. Eur J Cardiothorac Surg. 2001;20;25-9.

10. Conlan AA, Hurwitz SS, Krige 1, Nicolau N, Pool MB. Massive hemoptysis. Review of 123 cases. J Thorac Cardiovasc Surg. 1983;85:120-4.

11. Lee TW, Wan S, Choy DK, Chan M, Anifi A, Yun AP. Management of massive hemoptysis a single institution experience. Ann Thorac Cardiovasc Surg. 2000;6:232-5.

12. Alexander GR. A retrospective review comparing the treatment outcomes of emergency lung resection for massive haemoptysis with and without preoperative bronchial artery embolization. Eur J Cardiothorac Surg. 2014;45(2):251-5.

13. Kim YG, Yoon HK, Ko GY. Long-term effect of bronchial artery embolization in Korean patients with haemoptysis. Respirology. 2006;11(6):776-81.

14. Chun JY, Belli AM. Immediate and long-term outcomes of bronchial and non-bronchial systemic artery embolisation for the management of haemoptysis. Eur Radiol. 2010;20(3):558-65.

15. Lee JH, Kwon SY, Yoon HI. Haemoptysis due to chronic tuberculosis vs. bronchiectasis: comparison of long-term outcome of arterial embolisation. Int $\mathbf{J}$ Tuberc Lung Dis. 2007;11(7):781-7.

16. Slattery MM, Keeling AN, Lee MJ. Outcome and complications of bronchial artery embolisation for life-threatening haemoptysis. Ir J Med Sci. 2009;178(2):155-9.

17. Kaukuntla HK, Amer KM, Honeybourne D, Stableforth DE, Khalil-Marzouk JF, et al. Extrapleural bronchial artery ligation for lifethreatening hemoptysis in cystic fibrosis: a case report. Antiology. 2000;51(9):787-92.

18. Cipolli M, Perini S, Valletta EA. Bronchial artery embolization in the management of hemoptysis in cystic fibrosis. Pediatr Pulmonol. 1995;19(6):344-7.

19. Vidal V, Therasse E, Berthiaume Y, Bommart S, Giroux MF, Oliva VL, et al. Bronchial artery embolization in adults with cystic fibrosis: impact on the clinical course and survival. J Vasc Interv Radiol. 2006;17(6):953-8.

20. Barben JU, Ditchfield M, Carlin JB, Robertson CF, Robinson PJ, Olinsky A, et al. Major haemoptysis in children with cystic fibrosis: a 20-year retrospective study. J Cyst Fibros. 2003;2(3):105-11.

Cite this article as: Chandra AS, Rajalingam K, Reddy KBV, Prasad PK. A study of lung resection for haemoptysis with or without preoperative bronchial artery embolisation. Int Surg J 2016;3:1351-5. 